\title{
Michelson interferometer system with acoustic optic filter and fiber Bragg grating for reduction of four-wave mixing
}

\author{
Sistema de Interferômetro de Michelson com Filtro Acústico Óptico e Grade de Bragg para \\ Redução de Mistura de Quatro Ondas \\ F. B. de Sousa ${ }^{1 *}$; J. E. de Oliveira ${ }^{1}$; F. M. de Sousa ${ }^{1}$; M. B. C. Costa ${ }^{1}$; O. T. B. \\ de Oliveira $^{1}$; J. M. Oliveira ${ }^{1}$; E. S. Martins ${ }^{1}$; M. B. C. Costa ${ }^{1,2}$ \\ ${ }^{I}$ Programa de Pós-graduação em Engenharia Elétrica da Universidade Federal do Pará, Rua Augusto Corrêa, \\ 01, 68560000, Belém-Pará, Brasil. \\ ${ }^{2}$ Faculdade de Engenharia de Materiais da Universidade Federal do Pará, Rodovia BR-316, KM 7, Levilândia, \\ 67000000, Ananindeua - Pará, Brasil. \\ *fabiufpa@gmail.com
}

(Recebido em 27 de dezembro de 2018; aceito em 12 de maio de 2019)

In this paper a simplified design and efficient of a Michelson Interferometer (MI) system is presented, capable of reducing the Four-Wave Mixing (FWM) effects, using fiber Bragg grating and acoustic optic filter (FBG and AOF) with the aid of a highly non-linear photonic crystal fiber (HNL-PCF). The analysis of the MI system based in FBG and AOF was performed according to the effect of fiber length and input power by performance metrics: Optical Spectrum, maximum Quality factor (max. Q-factor), minimum bit error rate (min. BER), eye height, optical signal-to-noise ratio (OSNR) and timing jitter. The numerical simulation results showed that the MI system with FBG and AOF maintained a good signal performance, with Q-factor equal to 33.3 even after $100 \mathrm{~km}$ of single mode fiber (SMF) and with downstream signal power by up to $10 \mathrm{dBm}$.

Keywords: Michelson Interferometer, Acousto Optic Filter, Fiber Bragg Grating.

Neste trabalho é apresentado um projeto simplificado e eficiente de um sistema de interferômetro de Michelson (MI), capaz de reduzir os efeitos da mistura de quatro ondas (Four-Wave Mixing - FWM), usando grade de Bragg e filtro acústico óptico (fiber Bragg grating and acousto optic filter - FBG e AOF) com o auxílio de uma fibra de cristal fotônico altamente não linear (highly non-linear photonic crystal fiber - HNL-PCF). A análise do sistema MI baseado no FBG e AOF foi realizada de acordo com o efeito do comprimento da fibra e da potência de entrada pelas métricas de desempenho: Espectro Óptico, fator de Qualidade Máxima (máx. Fator Q), taxa de erro de bit mínima (min. BER), altura do olho, relação sinalruído (optical signal-to-noise ratio - OSNR) e timing jitter. Os resultados da simulação numérica mostraram que o sistema MI com FBG e AOF manteve bom desempenho do sinal, com fator Q igual a 33,3, mesmo após $100 \mathrm{~km}$ de fibra monomodo (single mode fiber - SMF) e com potência do sinal downstream de até 10 $\mathrm{dBm}$.

Palavras-chave: Interferometro de Michelson, Filtro Acustico Óptico, Fibra de Grade de Bragg.

\section{INTRODUCTION}

The need to implement long-distance communication projects is a current and future requirement for the purpose of facilitating people's access to information media around the world and this has become a reality with the creation of fiber optic networks [1]. However, attenuation and chromatic dispersion are two effects that must be taken into account in the creation of any fiber optic communication network design, because in the long-distance systems losses and distortions can occur in the signal, making it necessary to use of amplifiers, usually the Erbium Doped Fiber Amplifiers (EDFAs), which in addition to amplifying the signal, also emit Amplified Spontaneous Emission (ASE) noises, which are undesirable to the system [2], so the signal processing techniques are essentials.

The fiber optic, because it is a dielectric, responds non-linearly to the signal power intensities along the link length [3]. There are two categories of nonlinearities that can be observed in fiber optic communication systems, one is given by inelastic scattering processes: Stimulated Ramam Scattering (SRS) and Stimulated Brillouin Scattering (SBS). And the other is the variation of the 
refractive index of the fiber due to the intensity of the optical power, called Kerr effect: SelfPhase modulation (SPM) in single-channel system, Cross-Phase modulation (XPM) and FourWave Mixing) in multichannel system [2].

Recent research has revealed that the effect of FWM may be detrimental to the performance of the WDM and DWDM telecommunications systems, due to the crossings channels that may interfere with each other, but the use of control techniques of this data transfer characteristic to a wavelength can be very useful for sending data to a particular channel. There are several applications for the FWM effect, such as: parametric amplification, supercontinum generation, optical phase conjugation, demultiplexing of OTDM channels and Wavelength conversion of WDM channel [1]. In addition to these applications, knowing the dynamics of the FWM effect, it is possible to work with $2 \mathrm{R}$ or $3 \mathrm{R}$ signal regeneration techniques [3]; in WDM Radio-over-Fiber system [4]; in the FWM suppression by means of linear polarization techniques [5]; in hybrid modulation technique [6]; and in the optimization of systems, through variations in fiber length, signal strength, reference frequency and channel spacing [7].

The effect of FWM can considerably limit the performance of telecommunication systems over long-distance optical fiber. The high power of the input signal, the low frequencies, the number of channels and the reduction of the channel spacing are also considered as contributing factors for the increase of FWM, due to the change in fiber refractive index [5]. However, in this paper, we present an MI system model with FBG and AOF for wavelength selection and aiming to improve optical signal quality by reducing FWM crosstalk.

\section{THEORETICAL BASIS}

The optical fiber responds in a non-linear way when subjected to a strong power in its electromagnetic field. In this case the polarization induced by electric dipoles $P=\varepsilon_{0}\left(\chi^{(1)} \vec{E}+\chi^{(2)}: \vec{E} \vec{E}+\chi^{(3)}: \vec{E} \vec{E} \vec{E}+\ldots\right)$, is also not linear in the electric field $\vec{E}=\vec{E}_{0} \cos (\omega t-k z)$, where $\chi^{(j)}(j=1,2,3, \ldots)$ is $j$ th order susceptibility and $\varepsilon_{0}$ is the permittivity of vacuum [8]. In this sense, propagation of the signal in the optical fiber can be described by the simplified Non-Linear Schrödinger Equation (NLSE), which originates from the Maxwell's Equations given by [3]:

$$
\frac{\partial A(z, t)}{\partial z}+\frac{i}{2} \beta_{2} \frac{\partial^{2} A(z, t)}{\partial t^{2}}-\frac{1}{6} \beta_{3} \frac{\partial^{2} A(z, t)}{\partial t^{3}}+\frac{1}{2} \alpha A(z, t)=i \gamma|A(z, t)|^{2} A(z, t),
$$

where $A(z, t)$ is the complex amplitude of the optical signal, $\beta_{2}$ and $\beta_{3}$ are the second and third order Group Velocity Dispersion (GDV) parameters, $\gamma$ is the non-linear coefficient and $\alpha$ is the attenuation constant of the optical fiber. In the absence of dispersive effects, the Equation (1) can be solved analytically.

The chromatic dispersion or GVD at specific wavelength $\lambda$ can be calculated by the following equation [3]:

$$
D=-\frac{2 \pi c}{\lambda^{2}} \beta_{2} p s /(n m \cdot k m)
$$

where $c$ is the speed of light in the vacuum and $\beta_{2}$ is the GDV parameter that determines how much a signal widens as light propagates in the optical fiber.

When a HNLF-PCF with $L_{P C F}$ length and negative $-D_{P C F}$ dispersion is connected after a SMF with $L_{S M F}$ length and positive $D_{S M F}$ dispersion, the net dispersion must be zero. Thus the equation: $D_{S M F} \cdot L_{S M F}=-D_{P C F} \cdot L_{P C F}$ is satisfied [2]. This same equation is very useful in projects where there is a need to use two different optical fiber segments, such as a SMF and a PCF, thus having only the SMF length and the SMF and HNLF-PCF dispersion, so through of this equation makes it easy to determine the length of the HNLF-PCF required for the design of the project. 
The proposed optical fiber communication system used the FBG with filtering wavelengths. The Bragg wavelength $\lambda_{B}$ is dependent on the effective refractive index $n_{\text {eff }}$ and the grating period $\Lambda$ [9]:

$$
\lambda_{B}=2 n_{\text {eff }} \Lambda
$$

Therefore, the reflected wavelength in the FBG obeys the Bragg condition shown in Equation 3.

For a grating with modulation in $n_{\text {eff }}$ and $\Lambda$ uniform the maximum reflectivity is defined as [10]:

$$
R_{\max }=\tanh ^{2}\left(k L_{g}\right)
$$

where $L_{g}$ is the length of the grating e $k=\pi \Delta n_{\text {eff }} / \lambda_{B}$ is the coupling coefficient vector detuning factor and $\Delta n_{\text {eff }}$ is change in effective index.

The dispersion in a FBG with $\Lambda$ that varies linearly along $L_{g}$ is defined by [11]:

$$
D_{F B G}=\frac{2 n_{e f f} L_{g}}{c \Delta \lambda}
$$

where $\Delta \lambda$ is the difference between $\lambda_{B}$ initial and $\lambda_{B}$ final in the FBG.

The FWM effect is independent of the bit rate, but dependent on the refractive index of the optical fiber and power intensity of the signals that propagate in a WDM transmission system, in which various wavelengths are transmitted simultaneously and the optical power of a wavelength is transferred to the optical power of adjacent wavelength [5]. In this sense Figure 1 shows the degradation of the signal due to FWM in a two-channel WDM system.

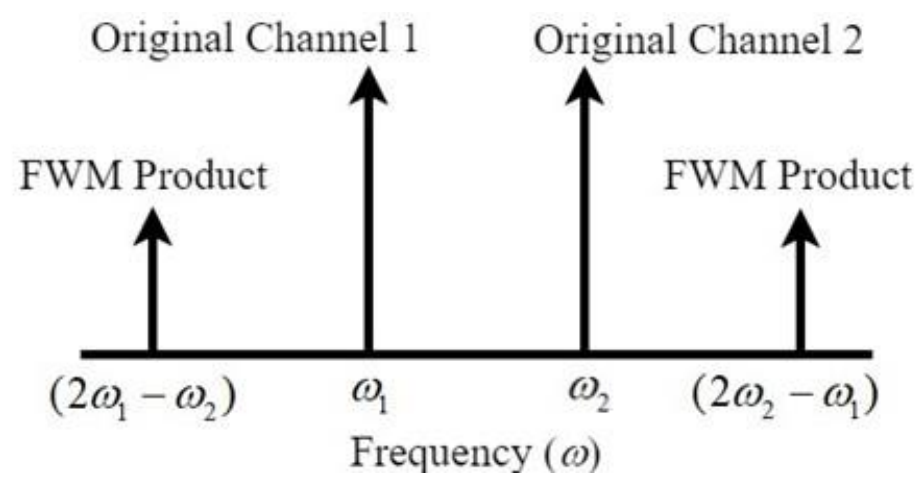

Figure 1: FWM effect in the frequency domain.

It can be seen from Figure 1 that the interaction between two original frequency waves $\omega_{1}$ and $\omega_{2}$ generated two new FWM products: $\left(2 \omega_{1}-\omega_{2}\right)$ and $\left(2 \omega_{2}-\omega_{1}\right)$, in such a way that $\left(\omega_{1}+\omega_{2}\right)=\left(2 \omega_{1}-\omega_{2}-2 \omega_{2}-\omega_{1}\right)$, this is due to the third-order susceptibility of the optical fiber. In this sense, according to Equation 6 , the number of sidebands $M$ grows geometrically with the increase in the number of communication channels $N$ [12].

$$
M=\left(\frac{N^{3}-N^{2}}{2}\right) \text {. }
$$

The performance of an optical receiver can be determined by the eye diagram, where Q-factor, OSNR and BER and timing jitter can be obtained. The Q-Factor is given by [3]: 


$$
Q=\frac{2 \sqrt{2} O S N R}{1+\sqrt{1+4 O S N R}} .
$$

The signal-to-noise ratio (OSNR) of the receiver for the best Q-factor is defined by [3]:

$$
\operatorname{OSNR}=\frac{1}{2} Q \cdot(Q+\sqrt{2}) .
$$

And the relationship between the BER and the Q-factor at the optimal threshold is expressed by [3]:

$$
B E R=\frac{1}{2} \operatorname{erfc}\left(\frac{Q}{\sqrt{2}}\right) \approx \frac{\exp \left(-Q^{2} / 2\right)}{Q \sqrt{2 \pi}}, \text { where } \operatorname{erfc}(x)=\frac{2}{\sqrt{\pi}} \int_{0}^{x} e^{-y^{2}} d y .
$$

Thus, for the good performance of the optical fiber communication system, ideal values are Qfactor $\geq 6$, BER $\leq 1 \times 10^{-9}$ and OSNR $\geq 22.24$ or $\geq 13.5 \mathrm{~dB}$. Therefore, as the power of the ASE noise increases, the gain of the amplifier decreases and consequently the BER increases, the OSNR and the Q-Factor decrease [2-3].

\section{SYSTEM SIMULATION PARAMETERS}

Figure 2 shows the MI system based on FBG and AOF, which was designed through the numerical Split-Step Fourier Method, where the results of the simulations were extracted for a transmission rate of 10 Gbps. In each Central Station downstream signals are externally modulated by Lithium Niobate Mach-Zehnder Modulators (LiNB-MZMs), both with a fixed extinction ratio of $20 \mathrm{~dB}$ with a voltage of $5.5 \mathrm{~V}$. The MZMs have two inputs: one for data generated by the (RBS) pulse generator, and another for optical carrier generated by each of the Continuous Wave (CWs) lasers with central wavelengths of $1550 \mathrm{~nm}$ and $1551 \mathrm{~nm}$. For both CWs the output power was set at $0 \mathrm{dBm}$ and variable from $-10 \mathrm{dBm}$ to $10 \mathrm{dBm}$ and with $10 \mathrm{MHz}$ linewidth.

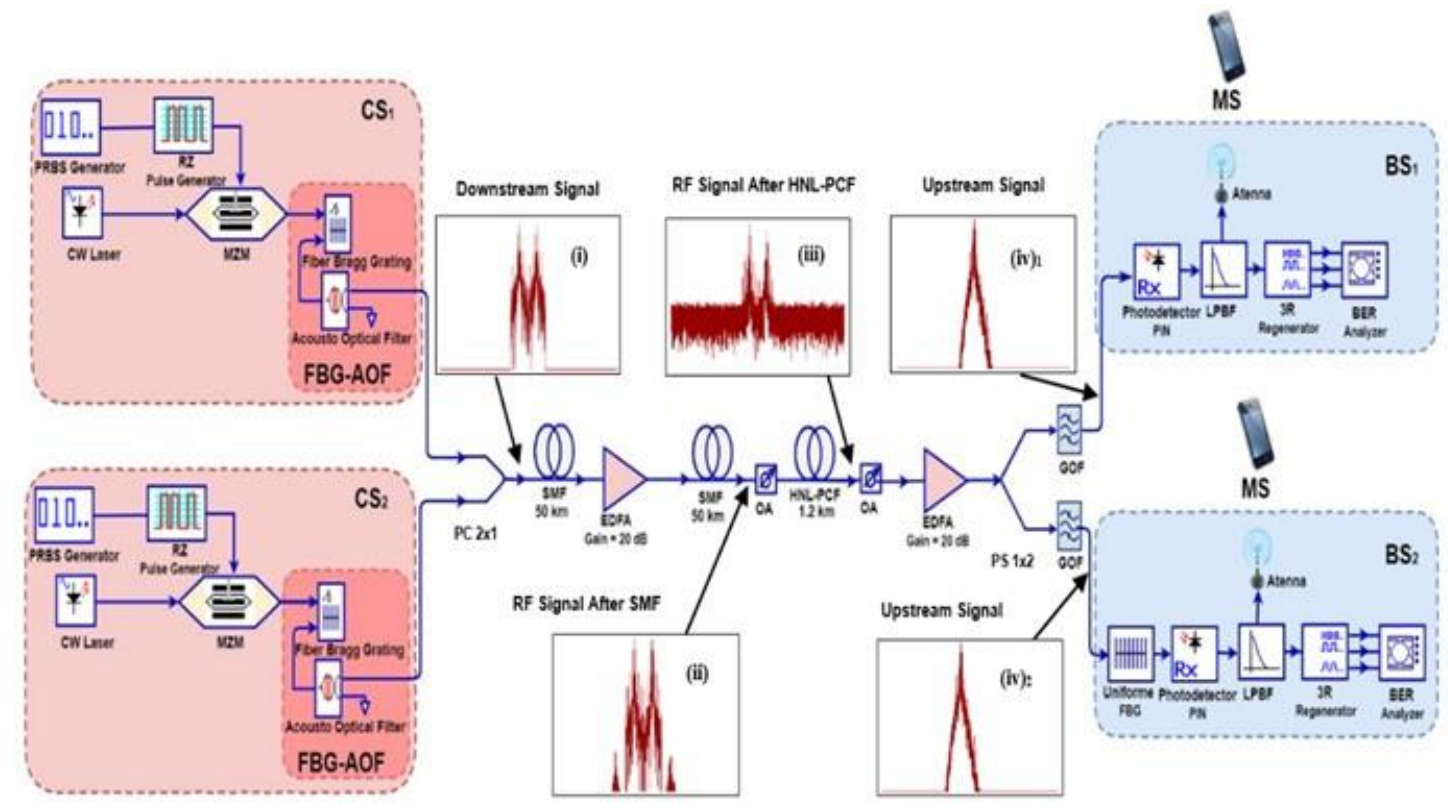

Figure 2: Block diagram of simulation setup.

In the outputs of Central Station $1\left(\mathrm{CS}_{1}\right)$ and Central Station $2\left(\mathrm{CS}_{2}\right)$, the downstreams signals underwent a dispersion pre-compensation process, through the FBGs and AOFs, with central frequencies corresponding to each of the CWs lasers. The downstreams signals were combined in a power combiner (PC) $2 \times 1$ and sent to a SMF that along its length induced the Four-Wave Mixing (FWM) effect. Then, the signal was amplified by an Erbium Doped Fiber Amplifier 
(EDFA), with gain of $20 \mathrm{~dB}$ and noise of $4 \mathrm{~dB}$. Optical attenuators (OAs) were also employed to define the launch power with better reception performance. The combined and amplified signal was sent to a HNL-PCF, which performed the Group Velocity Dispersion (GVD) mutual compensation in time domain and non-linear effects in the frequency domain, resulting in a sufficient amplification of the optical spectrum, but maintaining its temporal form, as shown in Figure 2 (iii). Then the signal was pre-amplified by another EDFA, with the same configuration as the previous one.

A Power Spliter (PS) 1x2 with $3.5 \mathrm{~dB}$ insertion loss was used to separate the signal to each of the Base Stations (BSs). Then each signal passed the Gaussian Optical Filter (GOF) with insertion loss of $4.5 \mathrm{~dB}$, bandwidth of $0.4 \mathrm{~nm}$ and with central wavelength set at $1550 \mathrm{~nm}$ for $\mathrm{BS}_{1}$ and 1551 $\mathrm{nm}$ for $\mathrm{BS}_{2}$. The GOFs were responsible for filtering Amplified Spontaneous Emission (ASE) noises sent by EDFAs. Each BS is composed of a photodetector PIN to produce frequencies in the electrical domain, with responsitivity of $1 \mathrm{~A} / \mathrm{W}$, and dark current $10 \mathrm{nA}$ the down sampling rate is $800 \mathrm{GHz}$ for the central wavelength $1550 \mathrm{~nm}$ for $\mathrm{BS}_{1}$ and $1551 \mathrm{~nm}$ for $\mathrm{BS}_{2}$, considering the thermal noise $2.048 \mathrm{e}-023 \mathrm{~W} / \mathrm{Hz}$. It is also composed of a Low Pass Bessel Filter (LPBF) to select the wavelengths in the $10 \mathrm{GHz}$ frequency, with a depth of $100 \mathrm{~dB}$ and a cutoff frequency of $0.75 \times \mathrm{Bit}$ rate $/ \mathrm{Hz}$. And at the output of each $\mathrm{BS}$ a $3 \mathrm{R}$ Regenerator was used to make the connection to the eye chart analyzer. We emphasize that $\mathrm{BS}_{2}$ consists of the same $\mathrm{BS}_{1}$ equipment plus an uniform FBG with bandwidth of $4 \mathrm{GHz}$ and maximum reflectivity of $97 \%$, which was responsible for reflecting wavelengths of $1551 \mathrm{~nm}$.

The parameters of simulations for SMF are: attenuation $(\alpha) 0.19 \mathrm{~dB} / \mathrm{km}$, dispersion $(D) 17$ $\mathrm{ps} / \mathrm{nm} / \mathrm{km}$, effective area $\left(A_{\text {eff }}\right) 76.30 \mu \mathrm{m}^{2}$, dispersion slope $(S) 0.08 \mathrm{ps} / \mathrm{nm}^{2} / \mathrm{km}$, nonlinear refractive index $\left(n_{\text {eff }}\right)$ of $2.6 \times 10^{-20} \mathrm{~m}^{2} / \mathrm{W}$ and length $(L)$ ranging from $25 \mathrm{~km}$ to $100 \mathrm{~km}$. And the parameters of simulations for PCF are: $(\alpha)$ of $5 \mathrm{~dB} / \mathrm{km},(D)$ of $-1215 \mathrm{ps} / \mathrm{nm} / \mathrm{km},\left(A_{\text {eff }}\right)$ of 1.80 $\mu \mathrm{m}^{2},(S)$ of $-0.25 \mathrm{ps} / \mathrm{nm}^{2} / \mathrm{km},\left(n_{\text {eff }}\right)$ of $2.6 \times 10^{-20} \mathrm{~m}^{2} / \mathrm{W}$ and $(L)$ of $0.2 \mathrm{~km}$ to $1.2 \mathrm{~km}$. For both optical fibers of the second and third order dispersion coefficients were equal to $\left(\beta_{2}\right)$ of -20 $\mathrm{ps}^{2} / \mathrm{km}$ and $\left(\beta_{3}\right)$ of $0 \mathrm{ps}^{3} / \mathrm{km}$ respectively.

\section{RESULTS AND ANALYSIS OF THE SIMULATIONS}

The metrics used for the analysis and discussion of the performance in the simulations of the proposed FBG and AOF based MI system were: Optical spectrum in frequency domain, Q-factor, BER, eye height, OSNR and timing jitter. The results were compared for MI systems with FBG and $\mathrm{AOF}$ and without FBG and AOF by varying the link length and signal strength in order to verify the FWM effects. In the simulations, the PCF was used only in the MI system with FBG and AOF. In this project, we used two types of viewers: The Optical Spectrum Analyzer (OSA) and the BER Analyzer.

The output spectra of $\mathrm{CS}_{1}$ and $\mathrm{CS}_{2}$ are shown in Figure 2 (i), these are signals with central wavelengths equal to $1550 \mathrm{~nm}$ and $1551 \mathrm{~nm}$. In this case the two signals are without degradation problems, that is, they were not influenced by non-linear and dispersive effects, since these measurements were made at the output of the transmitters.

The spectra of the signals after propagation in SMF in the FBG and AOF based MI system are shown in Figure 3. The result of Figure 3 (a) shows the optical spectra after pulse propagation in $100 \mathrm{~km}$ of SMF and with the power of the laser set at $0 \mathrm{dBm}$, it is noted that in this case there is the presence of FWM products and ASE noise. These undesirable effects are detrimental to the good performance of the signal transmission, as they interfere with the original channels, thus requiring treatment. Later the laser power was increased to $10 \mathrm{dBm}$, while the length of the SMF remained in $100 \mathrm{~km}$. As shown in Figure 3 (b), it was observed that increasing the power of the signal resulted in increased power of the FWM products. 

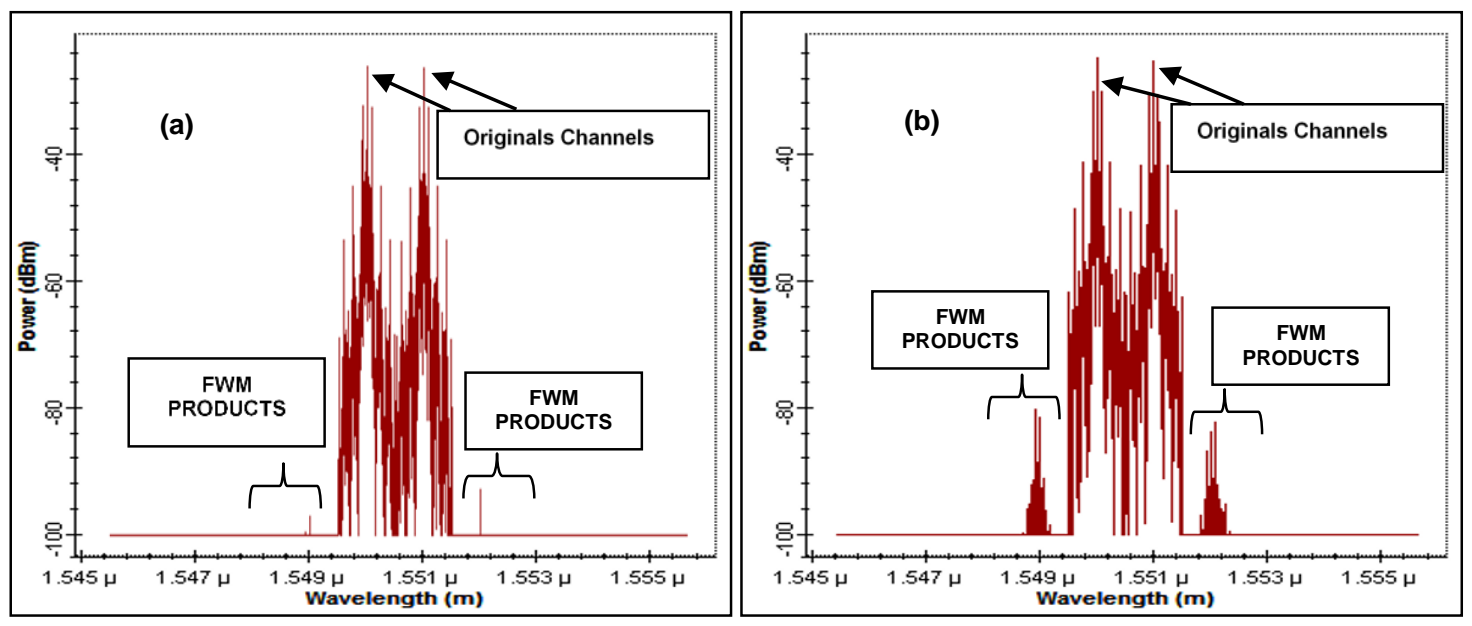

Figure 3. (a) Signal spectrum after propagation in $100 \mathrm{~km}$ of SMF with $0 \mathrm{dBm}$ of $C W$ laser power and (b) Signal spectrum after the spread in $100 \mathrm{~km}$ of SMF with $10 \mathrm{dBm}$ of CW laser power.

Figure 4 shows the graphs of the Q-Factor and log of BER versus the variation of transmission distance. In this case of the MI system without FBG and AOF and Downstream signal power at $0 \mathrm{dBm}$, for both $\mathrm{BS}_{1}$ and $\mathrm{BS}_{2}$ the quality factor decreased and the bit error rate increased with increasing transmission distance. Howere, the FWM effects were reduced for the FBG and AOF with HNLF-PCF MI systems, so a completely optical regeneration of the signal in each of the BSs was observed, as shown by the optical spectra in Figure 2 (iv) ${ }_{1}$ and Figure 2 (iv) 2 and also the clear eye diagrams in Figures 4 and 5 below.
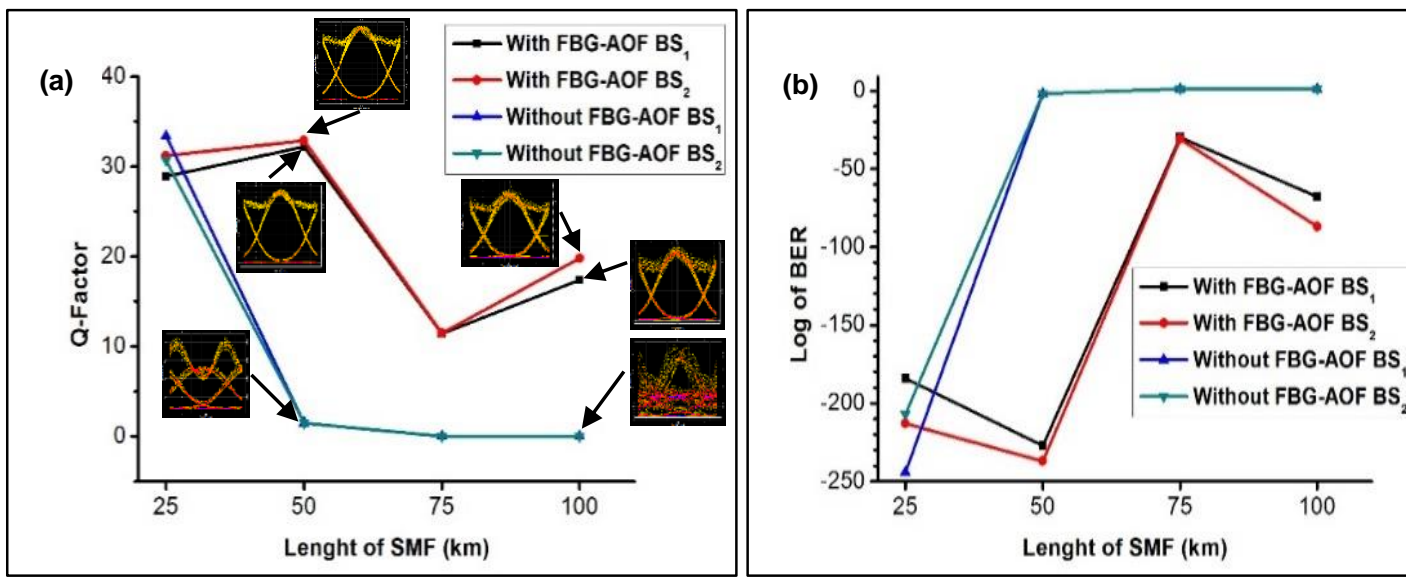

Figure 4. Q-Factor versus Lenght of SMF (a) and Log of BER versus Length of SMF $(b)$, both with 0 $\mathrm{dBm}$ of power and the eye diagrams of the signal at different transmission distances.

From Table 1, it can be observed that for the MI systems without FBG and AOF with $75 \mathrm{~km}$ and $100 \mathrm{~km}$ of SMF, the worst signal performance values were obtained, where the max. QFactors were equal to 0 , a min. BERs were equal to 1 and the eye heights were equal to 0 , for both $\mathrm{BS}_{1}$ and $\mathrm{BS}_{2}$, so the eye diagrams were considerably stressed, due to the increase of GVD that produced Intersymbol Interference, which affected the transmission of the signal. Therefore, with these performance values, the MI system without FBG and AOF with transmission distance of 75 $\mathrm{km}$ to $100 \mathrm{~km}$ is considered impractical.

Through the regenerated eye diagrams shown in the graphs of Figure 4 (a), it was observed that in the case of the MI system with FBG and AOF, an improvement of the system performance was obtained for both the received signal in $\mathrm{BS}_{1}$ and $\mathrm{BS}_{2}$, when compared to the MI system without FBG and AOF. In this sense, as shown in Table 2, in the MI system with FBG and AOF the max. Q-factors increased and min. BERs decreased, resulting in the decrease of the GVD and consequently of the Intersymbol Interference, so we obtained non-stressed eye diagrams and the free optical spectra of the presence of FWM. 
The graphs of Figure 5 below show the comparison of max. Q-Factor and the log of BER versus the variation of the signal power and with link length fixed in $100 \mathrm{~km}$ of SMF and $1.2 \mathrm{~km}$ of HNL-PCF. The results of the simulations were also obtained through the eye diagrams of the MI system with FBG and AOF and the MI system without FBG and AOF.

Table 1: Comparison of eye diagrams for different length of SMF.

\begin{tabular}{|c|c|c|c|c|}
\hline $\begin{array}{c}\text { MI System without FBG- } \\
\text { AOF }\end{array}$ & $\begin{array}{l}\text { Length of SMF } \\
(\mathbf{k m})\end{array}$ & $\begin{array}{l}\text { Max. Q- } \\
\text { Factor }\end{array}$ & $\begin{array}{l}\text { Min. } \\
\text { BER }\end{array}$ & $\begin{array}{r}\text { Eye } \\
\text { Height }\end{array}$ \\
\hline $\mathrm{BS}_{1}$ & \multirow[t]{2}{*}{25} & 33.4 & ${ }_{68}^{3.1 \times 10^{-}}$ & $3 \times 10^{-3}$ \\
\hline $\mathrm{BS}_{2}$ & & 30.7 & ${ }_{207}^{1.2 \times 10^{-}}$ & $2.9 \times 10^{-3}$ \\
\hline $\mathrm{BS}_{1}$ & \multirow[t]{2}{*}{50} & 1.5 & $7.2 \times 10^{-2}$ & $-6.3 \times 10^{-4}$ \\
\hline $\mathrm{BS}_{2}$ & & 1.5 & $7.2 \times 10^{-2}$ & $-6.3 \times 10^{-4}$ \\
\hline $\mathrm{BS}_{1}$ & \multirow[t]{2}{*}{75} & 0 & 1 & 0 \\
\hline $\mathrm{BS}_{2}$ & & 0 & 1 & 0 \\
\hline $\mathrm{BS}_{1}$ & \multirow[t]{2}{*}{100} & 0 & 1 & 0 \\
\hline $\mathrm{BS}_{2}$ & & 0 & 1 & 0 \\
\hline
\end{tabular}

Table 2: Comparison of eye diagrams for different length of SMF and PCF.

\begin{tabular}{|c|c|c|c|c|c|c|}
\hline $\begin{array}{l}\text { MI System with } \\
\text { FBG-AOF }\end{array}$ & $\begin{array}{r}\text { Length } \\
\text { of } \mathrm{HNL}- \\
\text { PCF }(\mathbf{k m})\end{array}$ & $\begin{array}{c}\text { Length } \\
\text { of SMF } \\
(\mathrm{km}) \\
\end{array}$ & $\begin{array}{l}\text { Max. Q- } \\
\text { Factor }\end{array}$ & $\begin{array}{l}\text { Min. } \\
\text { BER }\end{array}$ & $\begin{array}{r}\text { Eye } \\
\text { Height }\end{array}$ & $\begin{array}{l}\text { OSN } \\
\text { R } \\
\text { (dB) } \\
\end{array}$ \\
\hline $\mathrm{BS}_{1}$ & \multirow[t]{2}{*}{0.2} & \multirow[t]{2}{*}{25} & 29 & $\begin{array}{l}2.2 \times 10^{-} \\
184\end{array}$ & $\begin{array}{l}1.8 \times 1 \\
0^{-1}\end{array}$ & 37.3 \\
\hline$\overline{\mathrm{BS}_{2}}$ & & & 31.2 & $\underset{213}{2.3 \times 10^{-}}$ & $\begin{array}{l}1.8 \times 1 \\
0^{-1}\end{array}$ & 37.2 \\
\hline $\mathrm{BS}_{1}$ & \multirow[t]{2}{*}{0.5} & \multirow[t]{2}{*}{50} & 32.2 & $\underset{227}{1.9 \times 10^{-}}$ & $\begin{array}{l}4.4 \times 1 \\
0^{-2}\end{array}$ & 32.3 \\
\hline $\mathrm{BS}_{2}$ & & & 32.9 & $\begin{array}{l}1.4 \times 10^{-} \\
237\end{array}$ & $\begin{array}{l}4.4 \times 1 \\
0^{-2}\end{array}$ & 32.3 \\
\hline $\mathrm{BS}_{1}$ & \multirow[t]{2}{*}{1} & \multirow[t]{2}{*}{75} & 11.4 & $\begin{array}{l}2.4 \times 10^{-} \\
30\end{array}$ & $\begin{array}{l}4.8 \times 1 \\
0^{-4}\end{array}$ & 27.5 \\
\hline $\mathrm{BS}_{2}$ & & & 11.5 & $5 \times 10^{-31}$ & $2 \times 10^{-2}$ & 27.4 \\
\hline $\mathrm{BS}_{1}$ & \multirow[t]{2}{*}{1.2} & \multirow[t]{2}{*}{100} & 17.4 & $\begin{array}{l}5.4 \times 10^{-} \\
68\end{array}$ & $\begin{array}{l}1.8 \times 1 \\
0^{-3}\end{array}$ & 22.4 \\
\hline $\mathrm{BS}_{2}$ & & & 19.8 & $\underbrace{1.9 \times 10^{-}}_{87}$ & $\begin{array}{l}1.9 \times 1 \\
0^{-3}\end{array}$ & 22.3 \\
\hline
\end{tabular}



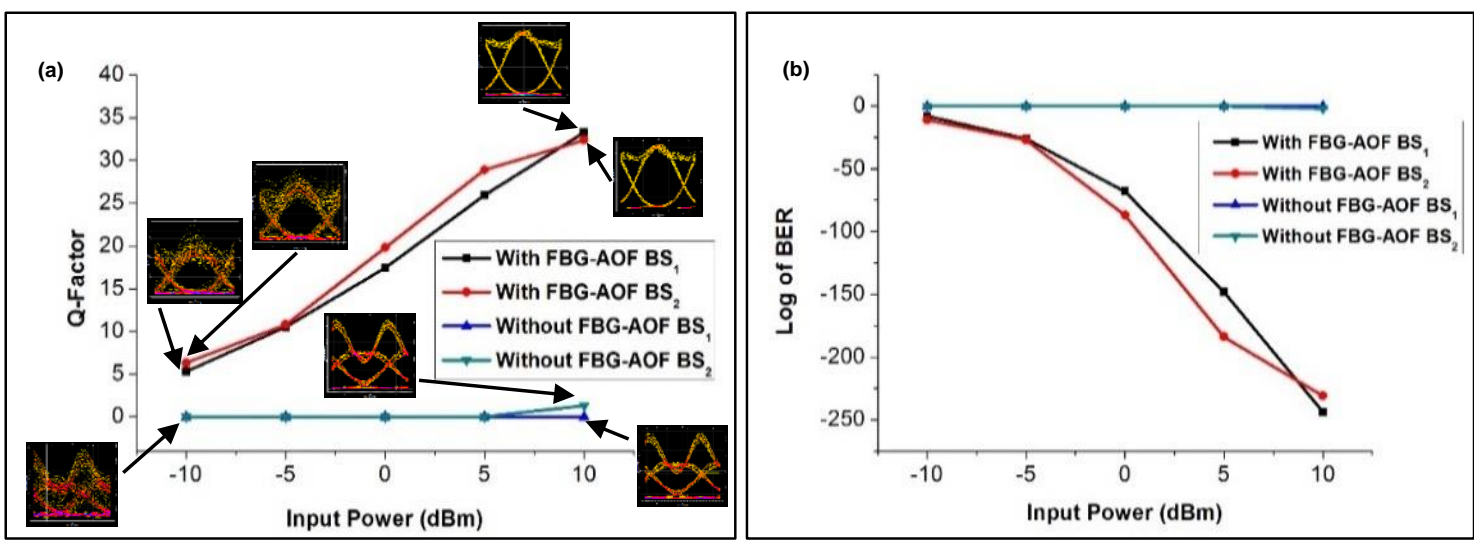

Figure 5. Q-Factor versus Input Power (a) and Log of BER versus Input Power (b), both with $100 \mathrm{~km}$ of SMF and the eye diagrams of the signal at different transmission power.

The results of Table 3 and the graphs in Figure 5 show that with the increase in signal power, for the MI system with FBG and AOF, the max. Q-Factor increased and min. BER decreased in both $\mathrm{BS}_{1}$ and $\mathrm{BS}_{2}$. However, for the MI system without FBG and AOF, the opposite occurred, the max. Q-Factor decreased and min. BER increased both $\mathrm{BS}_{1}$ and $\mathrm{BS}_{2}$.

The graphs in Figure 5 show that the received signal was considerably degraded for all values of input power variation in the MI without FBG and AOF, that is, the eye diagrams were stressed, so with these results the system becomes impractical. As shown in Table 4, in the case of the MI system without FBG and AOF, with signal powers of $-10 \mathrm{dBm},-5 \mathrm{dBm}, 0 \mathrm{dBm}$ and $5 \mathrm{dBm}$ for both the received signal in $\mathrm{BS}_{1}$ and in $\mathrm{BS}_{2}$ the same values were obtained of performance. Already for the case of the link with input power of $10 \mathrm{dBm}$ in $\mathrm{BS}_{1}$ it was obtained max. Q-Factor equal to 0 , min. BER equal to 1 and eye heigth equal to 0 , but in $\mathrm{BS}_{2}$ it was obtained max. Q-Factor equal to 1.3 , min. BER equal to $1 \times 10^{-1}$ and eye heigth equal to $-8 \times 10^{-4}$.

Table 3: Comparison of eye diagrams for different power of signal.

\begin{tabular}{|c|c|c|c|c|}
\hline $\begin{array}{c}\text { MI System with FBG- } \\
\text { AOF }\end{array}$ & $\begin{array}{c}\text { Power of } \\
\text { Signal (dBm) } \\
\end{array}$ & $\begin{array}{l}\text { Max. Q- } \\
\text { Factor }\end{array}$ & $\begin{array}{l}\text { Min. } \\
\text { BER }\end{array}$ & Eye Height \\
\hline $\mathrm{BS}_{1}$ & \multirow[t]{2}{*}{-10} & 5.3 & $3.3 \times 10^{-8}$ & $9.8 \times 10^{-5}$ \\
\hline $\mathrm{BS}_{2}$ & & 6.3 & $\underset{11}{8.3 \times 10^{-}}$ & $1.2 \times 10^{-4}$ \\
\hline $\mathrm{BS}_{1}$ & \multirow[t]{2}{*}{-5} & 10.5 & $\underset{26}{1.5 \times 10^{-}}$ & $5 \times 10^{-4}$ \\
\hline $\mathrm{BS}_{2}$ & & 10.8 & $\underset{27}{2.2 \times 10^{-}}$ & $5.1 \times 10^{-4}$ \\
\hline$\overline{\mathrm{BS}_{1}}$ & \multirow[t]{2}{*}{0} & 17.4 & $\underset{68}{5.4 \times 10^{-}}$ & $1.8 \times 10^{-3}$ \\
\hline$\overline{\mathrm{BS}_{2}}$ & & 19.8 & $\underset{87}{1.9 \times 10^{-}}$ & $1.9 \times 10^{-3}$ \\
\hline$\overline{\mathrm{BS}_{1}}$ & \multirow[t]{2}{*}{5} & 26 & $\begin{array}{l}2.3 \times 10^{-} \\
148\end{array}$ & $6.1 \times 10^{-3}$ \\
\hline $\mathrm{BS}_{2}$ & & 28.9 & $\begin{array}{l}3.4 \times 10^{-} \\
184\end{array}$ & $6.2 \times 10^{-3}$ \\
\hline$\overline{\mathrm{BS}_{1}}$ & \multirow[t]{2}{*}{10} & 32.4 & $\underset{231}{5.3 \times 10^{-}}$ & $2 \times 10^{-2}$ \\
\hline$\overline{\mathrm{BS}_{2}}$ & & 33.3 & $\frac{4.2 \times 10^{-}}{244}$ & $2 \times 10^{-2}$ \\
\hline
\end{tabular}


Table 4: Comparison of eye diagrams for different power of signal.

\begin{tabular}{c|c|c|c|c}
\hline $\begin{array}{c}\text { MI System without FBG- } \\
\text { AOF }\end{array}$ & \multirow{2}{*}{$\begin{array}{c}\text { Power of } \\
\text { Signal (dBm) }\end{array}$} & $\begin{array}{c}\text { Max. Q- } \\
\text { Factor }\end{array}$ & $\begin{array}{c}\text { Min. } \\
\text { BER }\end{array}$ & $\begin{array}{c}\text { Eye } \\
\text { Height }\end{array}$ \\
\hline $\mathrm{BS}_{1}$ & 10 & 0 & 1 & 0 \\
\hline $\mathrm{BS}_{2}$ & & 1.3 & $1 \times 10^{-1}$ & $-8 \times 10^{-4}$ \\
\hline $\mathrm{BS}_{1}$ & \multirow{2}{*}{5} & 0 & 1 & 0 \\
\hline $\mathrm{BS}_{2}$ & & 0 & 1 & 0 \\
\hline $\mathrm{BS}_{1}$ & \multirow{2}{*}{0} & 0 & 1 & 0 \\
\hline $\mathrm{BS}_{2}$ & & 0 & 1 & 0 \\
\hline $\mathrm{BS}_{1}$ & \multirow{2}{*}{-5} & 0 & 1 & 0 \\
\hline $\mathrm{BS}_{2}$ & & 0 & 1 & 0 \\
\hline $\mathrm{BS}_{1}$ & \multirow{2}{*}{-10} & 0 & 1 & 0 \\
\hline $\mathrm{BS}_{2}$ & & 0 & 1 & 0 \\
\hline
\end{tabular}

The jitter timing is also considered a metric to demonstrate system performance, in the case, the lower the timing jitter, the better the quality of the signal received. These values are measured at the crossing points with zero in the eye diagrams, these results were found through the difference between the time values of points A and B, as shown in Figure 6.
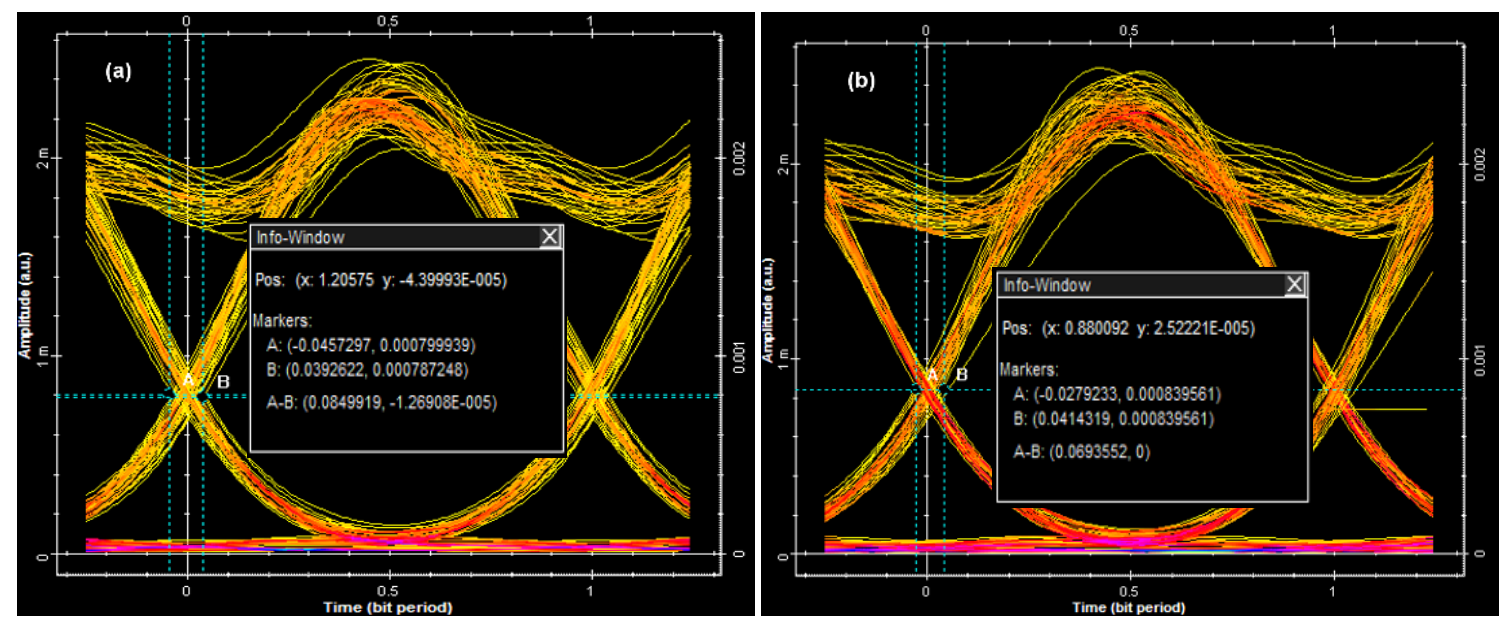

Figure 6. Timing jitter for the MI system with $F B G-A O F$, being (a) and (b) $B S_{1} B S_{2}$, both after $100 \mathrm{~km}$ of SMF and $1.2 \mathrm{~km}$ of $H N L-P C F$ and $O \mathrm{dBm}$ signal power.

Figure 6 shows the timing jitter values of the eye diagrams for the MI system with FBG and AOF with $100 \mathrm{~km}$ of SMF and $1.2 \mathrm{~km}$ of HNL-PCF and $0 \mathrm{dBm}$ of input power. For $\mathrm{BS}_{1}$ it was obtained a timing jitter approximately equal to $0.0849919 \mathrm{~ms}$, whereas for $\mathrm{BS}_{2}$ it was obtained a timing jitter approximately equal to $0.0693552 \mathrm{~ms}$ (Table 5). In this case, the receiver $\mathrm{BS}_{2}$ presented lower value of timing jitter. Table 5 shows the values of the timing jitters found at the signal output at $\mathrm{BS}_{1}$ and $\mathrm{BS}_{2}$ as a function of the variation of the SMF and HNL-PCF optical fiber lengths, which were used in the MI system with FBG and AOF.

Measurements of the timing jitter for the MI system without FBG and AOF were not performed as the results in the graphs of Figures 3 and 4 show that the eye diagrams for both $\mathrm{BS}_{1}$ and $\mathrm{BS}_{2}$ were very stressed due to non-linear and dispersive effects, so these causes made it impossible to perform such measurements. 
Table 5: Timing Jitter for the MI system with FBG-AOF.

\begin{tabular}{c|c|c|c}
\hline $\begin{array}{l}\text { Length of the } \\
\text { SMF (km) }\end{array}$ & $\begin{array}{c}\text { Length of the HNL- } \\
\mathbf{P C F}(\mathbf{k m})\end{array}$ & $\begin{array}{c}\text { Timing Jitter for } \\
\mathbf{B S}_{\mathbf{1}} \\
(\mathbf{m s})\end{array}$ & $\begin{array}{c}\text { Timing Jitter for } \\
\mathbf{B S}_{\mathbf{2}} \\
(\mathbf{m s})\end{array}$ \\
\hline 25 & 0.2 & 0.0373578 & 0.0402409 \\
\hline 50 & 0.5 & 0.0397134 & 0.0420275 \\
\hline 75 & 1 & 0.0931895 & 0.0957292 \\
\hline 100 & 1.2 & 0.0693552 & 0.0849919 \\
\hline
\end{tabular}

\section{CONCLUSION}

In our paper, we simulated a FBG and AOF-based MI system for the data rate of $10 \mathrm{~Gb} / \mathrm{s}$ in SMF and HNL-PCF. Through the presented results we can affirm that the MI system with FBG and AOF and with external modulation, can be considered an excellent alternative for the control of FWM, as demonstrated by the optical spectra and the eye diagrams. In the simulations obtained low values of min. BER and timing jitter and also high values of max. Q-Factor and OSNR, resulting in the good performance of the MI system with FBG and AOF. The results showed that with this scheme it was possible to achieve a mutual compensation of GVD and nonlinear effects. Therefore, this technique may be appropriate for the implementation of externally modulated optical fiber telecommunication systems.

\section{ACKNOWLEDGMENT}

This study was financed in part by the Coordenação de Aperfeiçoamento de Pessoal de Nível Superior - Brasil (CAPES) - Finance Code 001.

\section{REFERENCES}

1. Mishra BK, Jolly L, Mhatre K. Analysis of FWM effect in multichannel optical communication system. Global J Res Eng. 2013;13(3).

2. Keiser G. Optical fiber communications. McGraw-Hill. 2008.

3. Agrawal GP. Fiber-optic communication systems. John Wiley \& Sons, 2012.

4. Jain S, Therese A.B. Reduction of four wave mixing nonlinearity effect in WDM Radio over fiber systems. Indian J Sci Tech. 2015 Aug;8(19), doi: 10.17485/ijst/2015/v8i19/86051.

5. Dehghani F, Emami F. Suppression of four wave mixing based on the pairing combinations of differently linear-polarized optical signals in WDM system. J Optoelectr Nanostruc. 2016;1(1):1-8.

6. Mehra R, Joshi A. Suppression of Four Wave Mixing in 8 channel DWDM system using Hybrid Modulation Technique. Int J Electr Electric Eng. 2014;7(2):97-108.

7. Singh M, Sharma V. Investigation of four wave mixing effect at different transmission power levels and channel spacing. Int J Comput Appl. 2015 Oct;128(1): 12-17.

8. Singh SP, Singh N. Nonlinear effects in optical fibers: Origin, management and applications. Prog Electromagn Res. 2007; 73:249-275.

9. Pandey AK, Agrawal N, Ashok A. Performance analysis of high speed optical communication using FBG. Int J Comput Appl. 2014 Feb; 135(6).

10. Gautam A, Kumar A, Singh RR, Priye V. Optical sensing and monitoring architecture for pipelines using optical heterodyning and FBG filter. Optik-Int J Light Electron Optics. 2016;127(20):9161-9166.

11. Neto B, Lima MJN, Texeira AL, Nogueira RN, Pinto JL, da Rocha JRF, André P. Modelização da Dispersão de um Compensador Dinâmico de Dispersão Cromática Baseado em Redes de Bragg de Período Variável Gravadas em Fibra Óptica. Electrón Telecom. 2005 Marc;4(4):531-535.

12. Singh N, Goel AK. Analysis of Four Wave Mixing Effect at Different Channel Spacing in DWDM Systems Using EDFA with Single Pump Source. An International J Eng Sci. 2016 Jan; 17:382-389. 